\title{
Report from the Hand Osteoarthritis Working Group at OMERACT 2018: Update on Core Instrument Set Development
}

\author{
Ruth Wittoek (1), Féline P.B. Kroon (1), Burak Kundakci (1), Abhishek Abhishek (1D), \\ Ida K. Haugen (1), Francis Berenbaum ${ }^{(\mathbb{D})}$, Philip G. Conaghan ${ }^{\circledR}$, Mariko L. Ishimori ${ }^{(\mathbb{D})}$, \\ Wilma Smeets, Désirée van der Heijde (D), and Margreet Kloppenburg (i)
}

\begin{abstract}
Objective. To evaluate hand osteoarthritis tools for core instrument set development.
Methods. For OMERACT 2018, a systematic literature review and advances in instrument validation were presented.

Results. Visual analog and numerical rating scales were considered valuable for pain and patient's global assessment, despite heterogeneous phrasing and missing psychometric evidence for some aspects. The Modified Intermittent and Constant Osteoarthritis Pain scale was lacking evidence. The Michigan Hand Outcomes Questionnaire had advantages above other pain/function questionnaires. The Hand Mobility in Scleroderma scale was valid, although responsiveness was questioned. Potential joint activity instruments were evaluated.

Conclusion. The development of the core instrument set is progressing, and a research agenda was also developed. (First Release January 15 2019; J Rheumatol 2019;46:1183-7; doi:10.3899/jrheum.181003)
\end{abstract}

Key Indexing Terms:

\section{OMERACT HAND OSTEOARTHRITIS OUTCOME MEASUREMENT}

From the Department of Rheumatology, Ghent University Hospital, Ghent University, Ghent, Belgium; Department of Rheumatology, and Department of Clinical Epidemiology, Leiden University Medical Center, Leiden, the Netherlands; Division of Academic Rheumatology, University of Nottingham; National Institute for Health Research, Nottingham Biomedical Research Centre, Nottingham; Leeds Institute of Rheumatic and Musculoskeletal Medicine, University of Leeds; National Institute for Health Research (NIHR), Leeds Biomedical Research Centre, Leeds, UK; Department of Rheumatology, Diakonhjemmet Hospital, Oslo, Norway; Department of Rheumatology, Sorbonne Université, INSERM, SaintAntoine Hospital AP-HP, DHU i2B, Paris, France; Department of Medicine, Division of Rheumatology, Cedars-Sinai Medical Center, Los Angeles, California, USA.

PGC is supported in part by the UK NIHR Leeds Biomedical Research Centre.

R. Wittoek, MD, PhD, Department of Rheumatology, Ghent University Hospital, Ghent University; F.P. Kroon, MD, Department of

Rheumatology, Leiden University Medical Center; B. Kundakci, PT, MSc, Division of Academic Rheumatology, University of Nottingham;

A. Abhishek, MD, MRCP, PhD, Division of Academic Rheumatology, University of Nottingham, and National Institute for Health Research, Nottingham Biomedical Research Centre; I.K. Haugen, MD, PhD, Department of Rheumatology, Diakonhjemmet Hospital; F. Berenbaum, $M D, P h D$, Department of Rheumatology, Sorbonne Université, INSERM, Saint-Antoine hospital AP-HP, DHU i2B; P.G. Conaghan MBBS, PhD,

FRACP, FRCP, Leeds Institute of Rheumatic and Musculoskeletal Medicine, University of Leeds, and National Institute for Health Research, Leeds Biomedical Research Centre; M.L. Ishimori, MD, Department of Medicine, Division of Rheumatology, Cedars-Sinai Medical Center;

W. Smeets, Patient Representative, Department of Rheumatology, Leiden University Medical Center; D. van der Heijde, MD, PhD, Department of Rheumatology, Leiden University Medical Center; M. Kloppenburg, MD, PhD, Department of Rheumatology, and Department of Clinical Epidemiology, Leiden University Medical Center

Address correspondence to Dr. M. Kloppenburg, Department of Rheumatology, Leiden University Medical Center, PO Box 9600, 2300 RC, Leiden, the Netherlands.E-mail: g.kloppenburg@lumc.nl

Accepted for publication November 14, 2018.
Hand osteoarthritis (OA) is a highly prevalent disorder, causing a considerable burden of disease ${ }^{1}$. Simultaneous involvement of multiple hand joints and presence of different subsets (e.g., nodal, thumb base, and erosive OA) make it difficult to study. To advance our understanding, high-quality studies with optimal outcome measurement are essential.

The Outcome Measures in Rheumatology (OMERACT) Hand OA Working Group (WG), assembled in 2010, endorsed a core domain set for clinical trials of symptom and structure modification and observational studies at OMERACT $2014^{2}$, which was included in the Osteoarthritis Research Society International recommendations for design and conduct of clinical trials in hand $\mathrm{OA}^{3}$. The core domain set includes 6 domains for all settings [pain, physical function, patient's global assessment (PtGA), health-related quality of life (HRQOL), joint activity, and hand strength], and 2 additional domains for trials of structure modification and observational studies (hand mobility and structural damage). HRQOL and hand mobility are not mandatory domains.

A preliminary core instrument set was also proposed including visual analog (VAS) or numerical rating scales (NRS) for pain, Functional Index for Hand OA (FIHOA), tender joint count, and pinch/grip strength ${ }^{2}$. Subsequent goals of the WG were to (1) evaluate relevant instruments according to The OMERACT Handbook ${ }^{4}$, and (2) update the research agenda on the final core instrument set selection ${ }^{5}$. Progress was discussed at OMERACT 2018.

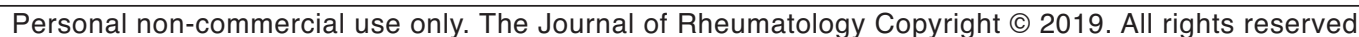




\section{MATERIALS AND METHODS}

Instrument and domain selection. The selection of instruments and domains presented and discussed at OMERACT 2018 were based on the needs addressed in the previous research agenda. Several discussions among members of the hand OA WG were held during the annual meetings of European League Against Rheumatism (2016, 2017) and the American College of Rheumatology (2017) and during a telephone conference organized by the steering committee (April 2017) prior to OMERACT 2018 to guide the program of the special interest group meeting (SIG).

Review of instruments measuring pain and PtGA. A systematic literature review (SLR) was performed (RW, BK, AA) including studies reporting on hand pain and PtGA measured on VAS or NRS in patients with hand OA. A previous SLR on measurement properties of pain and function instruments in hand OA until January 2014 was used as a basis ${ }^{6}$. Relevant manuscripts from that SLR were extracted. Additionally, medical literature databases (PubMed, Embase, Web of Science, COCHRANE, CINAHL, Academic Search Premier, ScienceDirect) were searched from January 2014 to January 2018 applying similar methodology as the 2014 SLR (see Supplementary File, available with the online version of this article). Psychometric features of the scales, such as reliability, responsiveness, construct validity, and clinical trial discrimination, were extracted and evaluated according to The OMERACT Handbook ${ }^{4}$. These features were discussed at OMERACT 2018 during the SIG meeting that was attended by 24 participants representing clinicians, researchers, patients, and regulatory authorities.

Special attention was given to the phrasing and other details of the VAS/NRS question.

Construct validity of the modified Intermittent and Constant OA Pain (ICOAP; IKH ${ }^{7,8,9}$ ) was studied in the Nor-Hand study to investigate whether constant and intermittent pain were separate constructs in hand $\mathrm{OA}$.

Investigation of other potential core instruments. Work was conducted by WG members on the relevant validity and psychometric properties of other tools: (1) properties of the Michigan Hand Outcomes Questionnaire (MHQ; $\mathrm{FK}^{10,11}$ ) were compared to more commonly used hand OA questionnaires, specifically the Australian/Canadian Hand OA Index (AUSCAN) and FIHOA $^{12,13}$; (2) performance of Hand Mobility in Scleroderma (HAMIS) and its responsiveness was compared to other mobility instruments $\left(\mathrm{FK}^{14}\right)$; and (3) assessment of tender joint count to measure joint activity ( $\mathrm{FK}^{15,16}$ ).

Research agenda. Guided by discussions prior to and at OMERACT 2018, a research agenda was developed.

\section{RESULTS}

Domain pain and PtGA: progress in instrument validation. From the previous SLR, 32 relevant manuscripts were selected, providing data on VAS/NRS pain and/or $\mathrm{PtGA}^{6}$. Since January 2014, 18 relevant manuscripts were published and could be added ( $\mathrm{S} 1-\mathrm{S} 50$, see reference list in the Supplementary File, available with the online version of this article). Details of all included manuscripts can be found in Supplementary Table 1. Summary results of the search (Supplementary Figure 1) and psychometric features of both scales within these domains were discussed by the WG (Table 1). VAS range $0-100 \mathrm{~mm}$ was the most studied scale (in $26 / 46$ studies for pain and 10/15 studies for PtGA). No study reported test-retest reliability data on the use of either scale in these domains. For pain, good construct validity of VAS was shown (S3, S24, S50), while only limited data were available for NRS (S41). Twenty-two (S1, S2, S4, S6-S13, S15-S18, S21, S22, S26, S37, S38, S42, S46) and 8 studies (S15, S25, S28, S33, S34, S41, S45, S47) showed evidence for responsiveness of VAS and NRS, respectively, and 13 (S7-S12, S17,
S21, S22, S26, S37, S38, S46) and 6 studies (S14, S28, S33, S34, S41, S47) for clinical trial discrimination for VAS and NRS, respectively.

For PtGA, construct validity was not studied. Evidence to support responsiveness for VAS was available in 10 studies (S3, S6, S12, S13, S15, S18, S22, S29, S38, S40), and 3 studies for NRS (S14, S28, S45). The capacity to discriminate in clinical trials was shown for VAS PtGA in agreement with the primary outcome in 5 studies (S12, S22, S29, S38, S40), while only 1 study supported this for NRS (S28).

Strikingly, phrasing of the question accompanying VAS/NRS in both domains was very heterogeneous, and details were often not reported. For pain, substantial variety existed in which aspect(s) of pain were assessed (e.g., pain at rest or upon exertion, average or worst pain), location and joint(s) referred to (e.g., target joints, dominant hand, both hands), and time of recall (undefined or ranging from current to 2 weeks; Supplementary Table 2, available with the online version of this article). Similarly, for PtGA, time of recall was undefined in most studies (3/15 studies did specify; all 48 h; Supplementary Table 3). After presentation of these findings at OMERACT 2018, the WG proposed that clear standardized phrasing accompanying these instruments be defined for pain and PtGA. It was proposed that PtGA should assess the effect of the disease on the patient's general well-being. Review of results of previously held focus groups was suggested to analyze what is most relevant to patients ${ }^{17}$.

Results of the validation study of the modified ICOAP were discussed at OMERACT 2018. Detailed results are presented elsewhere $^{9}$. In short, in patients with hand OA, constant and intermittent pain largely overlapped and were not separate constructs, in contrast to the situation in knee and hip $\mathrm{OA}^{7,8}$. The existence of separate constructs in hand OA seemed clinically plausible but might be influenced by hand OA location (finger vs thumb base) and involvement of multiple hand joints at different disease stages. It was suggested to seek more patient input, since the development of ICOAP was based on focus group discussions with patients with knee and hip OA, but not hand OA. However, previous focus groups of patients with hand OA have already identified a range of pain concepts, such as fluctuating pain and psychological consequences of pain, which are not represented in the commonly used instruments to assess hand $\mathrm{OA}^{17}$.

Based on the available evidence, it was concluded that VAS and NRS are most likely the best instruments to measure pain and PtGA. However, evidence about some essential psychometric properties is missing, in particular regarding reliability, construct validity for NRS pain/PtGA, and clinical trial discrimination for NRS PtGA.

Evaluation of other potential core instruments and research agenda. The results of comparison of MHQ with AUSCAN and FIHOA for measuring domains of pain and function were discussed in light of OMERACT Filter 2.14 (Table

Personal non-commercial use only. The Journal of Rheumatology Copyright $\odot$ 2019. All rights reserved 


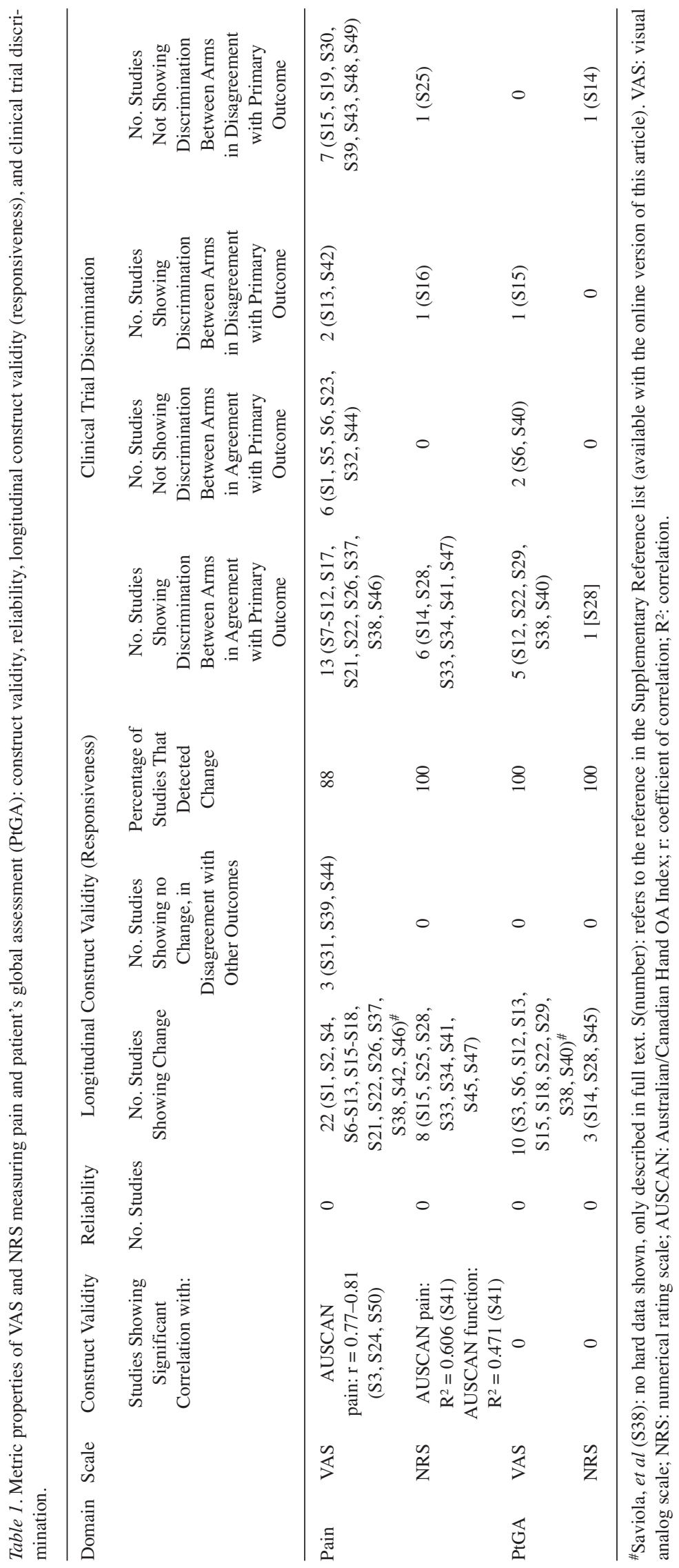

Personal non-commercial use only. The Journal of Rheumatology Copyright $\odot$ 2019. All rights reserved. 
Table 2. Comparison of properties of Michigan Hand Outcomes Questionnaire (MHQ), Australian/Canadian Hand Osteoarthritis Index (AUSCAN), and Functional Index for Hand Osteoarthritis (FIHOA).

\begin{tabular}{|c|c|c|c|}
\hline Variables & $\mathrm{MHQ}^{10}$ & AUSCAN $^{12}$ & FIHOA $^{13}$ \\
\hline \multicolumn{4}{|l|}{ Domain: Pain } \\
\hline No. items & 5 & 5 & - \\
\hline Aspect of pain assessed & $\begin{array}{l}\text { Frequency of experiencing pain } \\
\text { veral situations (in general, during sleep } \\
\text { or ADL) and whether it affects the } \\
\text { respondent's happiness }\end{array}$ & $\begin{array}{l}\text { Pain severity during rest and } \\
\text { several tasks (lifting, } \\
\text { squeezing, turning, gripping) }\end{array}$ & - \\
\hline Specific other comments & No & No & - \\
\hline \multicolumn{4}{|l|}{ Domain: Function } \\
\hline No. items & 11 hand function scale: $10 ;$ ADL scale: 17 & 9 & 10 \\
\hline Floor and ceiling effects* & $\begin{array}{l}\text { No (subscales overall hand function/ } \\
\text { ADL: } 0 \% / 0 \% \text { with lowest score, } \\
1.3 \% / 3.1 \% \text { with highest score) }\end{array}$ & $\begin{array}{l}\text { No ( } 1.8 \% \text { with lowest score, } \\
0.3 \% \text { with highest score) }\end{array}$ & $\begin{array}{l}\text { No ( } 4.2 \% \text { with lowest score, } \\
0 \% \text { with highest score })\end{array}$ \\
\hline Specific other comments & arate assessment of left and right hand & No & $\begin{array}{c}\text { Some items may be culturally } \\
\text { challenging (accepting a handshake), } \\
\text { or outdated (writing for more than } \\
10 \text { min; women sew and men } \\
\text { use a screwdriver) }\end{array}$ \\
\hline non & $\begin{array}{l}\text { Freely available for academic or } \\
\text { aprofit institutions, permission needed } \\
\text { gefore use (online application form) }\end{array}$ & $\begin{array}{l}\text { Copyrighted, payment of fee, and } \\
\text { permission needed before use }\end{array}$ & No \\
\hline Available in multiple languages & Yes & Yes & Yes \\
\hline $\begin{array}{l}\text { Interpretability comments } \\
\qquad \text { opposit }\end{array}$ & $\begin{array}{l}\text { Pain scale must be interpreted in } \\
\text { ite direction compared to other subscales }\end{array}$ & No & No \\
\hline
\end{tabular}

*Data reviewed in HOSTAS cohort $(\mathrm{n}=383)$, Leiden University Medical Center, Leiden, the Netherlands. ADL: activities of daily living; N/A: not available; VAS: visual analog scale.

$\left.2^{10,12,13}\right)^{11}$. While displaying similar measurement properties, important advantages of MHQ above other instruments were that it can overcome issues of copyright (AUSCAN) and outdated questions (FIHOA). The possibility to propose more than 1 instrument for a core domain, with the accompanying risk of jeopardizing standardization, was discussed.

Assessment of HAMIS performance in comparison to other mobility instruments was published previously ${ }^{14}$. Though HAMIS appeared the most useful to measure hand mobility compared to other instruments, the WG debated that responsiveness data are weak. Over a 2-year period, limited change over time was observed ${ }^{14}$, either indicating that the domain itself does not change, or that the instrument cannot detect this change.

Progress in instrument development for joint activity is published in conference abstracts ${ }^{15,16}$. Lack of a well-accepted definition hampers instrument development for this domain. Potential instruments include ultrasound and 
magnetic resonance imaging to detect inflammation, palpation to reveal pain, self-reported painful joint count, soft tissue swelling, and pain while gripping. In the $\mathrm{WG}$ discussion, it was suggested that some instruments complement each other, and a combination may be useful. Prediction of radiological progression was proposed as an anchor to assess suitable instruments.

Following discussion of these results, an agenda was developed to guide future research (Table 3 ).

\section{DISCUSSION}

Progress results were presented and discussed regarding the development of a core instrument set for hand OA. The core instrument set was developed through investigation of the psychometric properties of candidate instruments according to The OMERACT Handbook ${ }^{4}$, assessing construct validity, reliability, responsiveness, and clinical trial discrimination. The results serve as the basis of an updated research agenda.

\section{ONLINE SUPPLEMENT}

Supplementary material accompanies the online version of this article.

\section{REFERENCES}

1. Kloppenburg M, Kwok WY. Hand osteoarthritis - a heterogeneous disorder. Nat Rev Rheumatol 2011;8:22-31

2. Kloppenburg M, Bøyesen P, Visser AW, Haugen IK, Boers M, Boonen A, et al. Report from the OMERACT hand osteoarthritis working group: set of core domains and preliminary set of instruments for use in clinical trials and observational studies. J Rheumatol 2015;42:2190-7.

3. Kloppenburg M, Maheu E, Kraus VB, Cicuttini F, Doherty M, Dreiser RL, et al; OARSI Hand Clinical Trial Recommendations Work Group. OARSI Clinical Trials Recommendations: Design and conduct of clinical trials for hand osteoarthritis. Osteoarthritis Cartilage 2015;23:772-86.

4. Boers M, Kirwan JR, Tugwell P, Beaton D, Bingham CO III, Conaghan PG, et al. The OMERACT Handbook. [Internet. Accessed May 17, 2017.] Available from: https://omeract.org/resources

5. Boers M, Kirwan JR, Wells G, Beaton D, Gossec L, d'Agostino MA, et al. Developing core outcome measurement sets for clinical trials: OMERACT filter 2.0. J Clin Epidemiol 2014;67:745-53.

6. Visser AW, Bøyesen P, Haugen IK, Schoones JW, van der Heijde
DM, Rosendaal FR, et al. Instruments measuring pain, physical function, or patient's global assessment in hand osteoarthritis: a systematic literature search. J Rheumatol 2015;42:2118-34.

7. Hawker GA, Davis AM, French MR, Cibere J, Jordan JM, March L, et al. Development and preliminary psychometric testing of a new OA pain measure - an OARSI/OMERACT initiative. Osteoarthritis Cartilage 2008;16:409-14.

8. Hawker GA, Stewart L, French MR, Cibere J, Jordan JM, March L, et al. Understanding the pain experience in hip and knee osteoarthritis - an OARSI/OMERACT initiative. Osteoarthritis Cartilage 2008; 16:415-22.

9. Gløersen M, Steen Pettersen P, Kvien TK, Haugen IK. Validation of the Intermittent and Constant Osteoarthritis Pain questionnaire in patients with hand osteoarthritis: results from the Nor-Hand study. J Rheumatol 2019;46:645-51.

10. Chung KC, Pillsbury MS, Walters MR, Hayward RA. Reliability and validity testing of the Michigan Hand Outcomes Questionnaire. J Hand Surg Am 1998;23:575-87.

11. Kroon FPB, Boersma A, Boonen A, van Beest S, Damman W, van der Heijde D, et al. Performance of the Michigan Hand Outcomes Questionnaire in hand osteoarthritis. Osteoarthritis Cartilage 2018;26:1627-35.

12. Bellamy N, Campbell J, Haraoui B, Buchbinder R, Hobby K, Roth $\mathrm{JH}$, et al. Dimensionality and clinical importance of pain and disability in hand osteoarthritis: development of the Australian/Canadian (AUSCAN) Osteoarthritis Hand Index. Osteoarthritis Cartilage 2002;10:855-62.

13. Dreiser RL, Maheu E, Guillou GB, Caspard H, Grouin JM. Validation of an algofunctional index for osteoarthritis of the hand. Rev Rhum Engl Ed 1995;62:43S-53S.

14. Kroon FP, Damman W, Liu R, Bijsterbosch J, Meulenbelt I, van der Heijde D, et al. Validity, reliability, responsiveness and feasibility of four hand mobility measures in hand osteoarthritis. Rheumatology 2018;57:525-32.

15. Damman W, Liu R, Kortekaas M, Rosendaal F, van der Heijde D, Kloppenburg M. Construct validity of the Doyle Index in the outcome domain of joint activity in hand osteoarthritis patients. Osteoarthritis Cartilage 2016;24:S434.

16. Kroon FP, van der Plas JL, van Beest S, Damman W, Kloppenburg M. Investigation of self-reported painful joint count as an outcome measure in hand osteoarthritis. Osteoarthritis Cartilage 2018;26:S213-S4.

17. Stamm T, van der Giesen F, Thorstensson C, Steen E, Birrell F, Bauernfeind B, et al. Patient perspective of hand osteoarthritis in relation to concepts covered by instruments measuring functioning: a qualitative European multicentre study. Ann Rheum Dis 2009;68:1453-60.

Table 3. Future research agenda to promote core instrument set selection for hand OA.

Definition of standardized phrasing for VAS and NRS pain and PtGA

Assessment of test-retest reliability of VAS and NRS pain and PtGA

Investigation of construct validity for NRS pain and PtGA, and discriminative capacity in clinical trials for NRS PtGA

Investigation of validity of combinations of instruments to assess joint activity, including, e.g., tender joints, self-reported painful joints, swollen joints, pain while gripping, and inflammatory signs on imaging Assessment of reliability of soft tissue joint swelling in hand OA Investigation of psychometric properties of grip and pinch strength to measure core domain hand strength Review of available instruments to assess health-related quality of life in hand OA, and development of a disease-specific instrument

Investigation of the metric properties of ultrasound and magnetic resonance imaging Investigation of the value of computed tomography

OA: osteoarthritis; VAS: visual analog scale; NRS: numerical rating scale; PtGA: patient's global assessment. 